\title{
Agroindústria familiar rural: uma estratégia para melhorar a qualidade de vida no espaço rural
}

\author{
Aline Weber Sulzbacher* \\ Cesar De David**
}

\section{Resumo}

Tradicionalmente o campo é visto como espaço atrasado, onde a população vive desconectada da sociedade dita moderna. No entanto, à medida que conquistam seu direito de participar do processo de construção de alternativas para melhorar a qualidade de vida da comunidade, tais sujeitos mostram a riqueza de suas iniciativas. Essa reflexão motivou esta pesquisa, que teve por objetivo compreender as formas de organização produtiva e as contribuições para a reafirmação e inclusão socioeconômica da agricultura familiar, promovidas com base em duas experiências de agroindústria familiar rural. Em estudos teóricos e trabalhos de campo foram colhidos dados que pudessem auxiliar a compreender o universo em foco. Como resultado, notou-se que a atividade vem contribuindo significativamente para promover a cidadania, ao gerar renda, emprego e participação na vida política municipal.

Palavras-chave: Agroindústria familiar rural; Sujeito rural; Desenvolvimento endógeno.

\footnotetext{
Geógrafa e Mestranda em Extensão Rural - CCR/UFSM (linewsulz@yahoo.com.br).

** Professor Departamento de Geociências - CCNE/UFSM (cdedavid@smail.ufsm.br).
}

Geosul, Florianópolis, v. 24, n. 47, p 69-90, jan./jun. 2009 
SULZBACHER, A.W. \& DAVID. Cesar De. Agroindústria familiar rural: ...

Rural family agro-industry: a strategy for the improvement of the quality of life in the rural space

\begin{abstract}
Traditionally, the country is seen as a place that is stuck in time, where the population lives disconnected from the modern society. However, as they conquer their right to participate on the process of building alternatives to improve the life quality of the comunity, these people show the richness of their initiatives. This reflection motivated this research, which has the objective of understanding the forms of productive organization and the contributions to socio - economical inclusion of the family agriculture, promoted taking in consideration two experiences of the agro-industry rural family. In teoric studies and field work data was colected in order to help understand the universe in question. As a result, we noticed that the activity is contributing to promote the citizenhood, generating income, jobs and participation on the district's political life.

Key words: Rural family agribusiness; Rural subject; Endogenous development.
\end{abstract}

\title{
Introdução
}

O espaço rural é pleno de conflitos: na relação sociedade e natureza, na busca incessante pelo domínio das forças naturais, na preservação e/ou conservação do meio ambiente. Um conflito marcado principalmente pelas relações humanas: o homem como sujeito transformador se alia aos fatores de produção, reorganiza-se e mescla-se com os aspectos culturais e naturais, configurando um contexto territorial permeado pela diversidade de fenômenos e atores sociais.

Nesse complexo rol de relações sociais e de produção, emergem problemáticas que desafiam a busca por soluções, por alternativas comprometidas com uma transformação social e, 
SULZBACHER, A.W. \& DAVID. Cesar De. Agroindústria familiar rural: ...

portanto, que contribuam para reduzir os diferentes conflitos que permeiam o espaço rural.

Assim, este artigo atenta fundamentalmente para um processo de desenvolvimento endógeno que vem sendo identificado em diferentes regiões do Brasil e que se consolida através da cooperação e do resgate da cultura rural: a agroindústria familiar rural. Sua excepcionalidade não consiste somente na iniciativa dos agricultores familiares, mas sim na indispensável convergência de instituições e órgãos público-privados para que a atividade se viabilize e se constitua numa alternativa para a agricultura.

Essa questão será analisada tomando-se por base duas agroindústrias familiares rurais no município de Chapada/RS, buscando compreender as suas formas de organização produtiva e as contribuições para a reafirmação e inclusão socioeconômica da agricultura familiar. Os procedimentos metodológicos incluíram estudos teóricos e trabalhos a campo, a fim de colher dados que pudessem auxiliar a compreender o universo em foco.

\section{O espaço geográfico de Chapada-RS}

No estudo da atividade agroindustrial familiar rural no município de Chapada, cumpre destacar as características que compõem o seu território, principalmente por sua capacidade para promover a inclusão socioeconômica.

Com uma área de $684,04 \mathrm{~km}^{2}$ e em média 436 metros de altitude, o município de Chapada situa-se na porção norte do Estado do Rio Grande do Sul (Figura 01), classificada pelo Instituto Brasileiro de Geografia e Estatística (IBGE, 2000) como integrante da Microrregião de Carazinho. Comporta atualmente uma população estimada em 9.746 habitantes assim distribuídos: $48,59 \%$ na zona urbana e $51,41 \%$ na zona rural. Sua densidade demográfica pode ser considerada baixa, de $14,03 \mathrm{hab} / \mathrm{km}^{2}$, se comparada com a da microrregião geográfica de Carazinho, que é $32,11 \mathrm{hab} / \mathrm{km}^{2}$. 


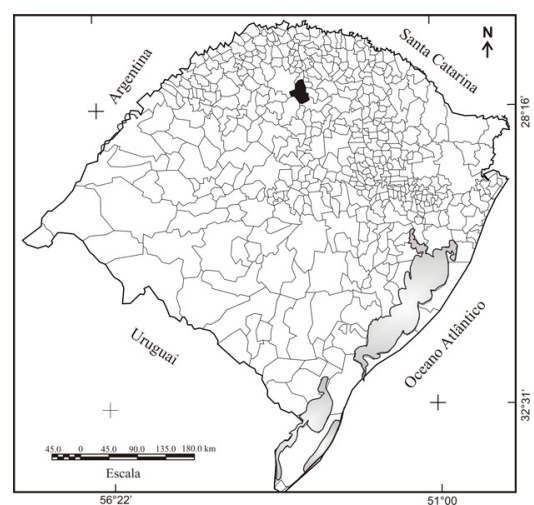

Figura 01: Mapa de localização do município de Chapada-RS. Fonte: IBGE - Base Municipal, 2001 (adaptado).

A emancipação político-administrativa de Chapada ocorreu em 1959, através da Lei $\mathrm{n}^{\circ}$ 3.712, por desmembramento dos municípios de Palmeira das Missões e Sarandi. Em 03 de junho do mesmo ano tomaram posse a primeira Câmara de Vereadores e o primeiro Prefeito. Esse fato representa, territorial e culturalmente, a conquista de uma autonomia política que acena com a possibilidade de um desenvolvimento pautado nos interesses da comunidade local.

Situado no entorno de centros com boas perspectivas de consumo, o município goza de uma localização geográfica estratégica, próxima de municípios como Palmeira das Missões, Carazinho e, mais incisivamente, Passo Fundo (distante cerca de $100 \mathrm{~km}$ ), cidades de médio porte e com uma economia baseada na produção agrícola de larga escala, não atendendo ao mercado consumidor interno. Esse é um fator a ser considerado quando se pretende buscar alternativas para o desenvolvimento das unidades de produção familiar.

A presença dos descendentes de imigrantes europeus foi de vital importância para o desenvolvimento e a caracterização atual do município. Os primeiros descendentes alemães chegam por volta de 1922, e os italianos de 1928. Registros pesquisados por 
SULZBACHER, A.W. \& DAVID. Cesar De. Agroindústria familiar rural: ...

Roche (1969) datam de 1915, quando da formação de uma colônia particular em Tesouras, atual distrito de Chapada.

Em Chapada, a organização da colonização e das suas atividades obedeceu a alguns critérios relacionados basicamente ao credo religioso, ao parentesco e ao espírito comunitário. Este último foi de fundamental importância para a superação das dificuldades, tendo em vista a realidade inóspita. A formação cultural das colônias velhas, marcada por festas religiosas, atividades de lazer e diversão, foi mesclando-se com as influências dos lusos e dos caboclos ${ }^{1}$ que já habitavam a região, principalmente de Palmeira das Missões, onde algumas atividades foram perdendo-se no tempo e substituídas, enquanto outras ainda resistem até hoje (STEFFEN, 1984).

Ao abordar a colonização européia no Estado, Roche (1969, p. 250) lembra que "das culturas [agrícolas] que se impuseram aos colonos alemães e constituíram o essencial de seus recursos, nenhuma tem origem européia". Esse mesmo autor destaca algumas culturas que compunham a agricultura inicial, dentre os quais a batata-inglesa, a cana-de-açúcar, o fumo, a mandioca, o milho e o feijão-preto. Esses produtos passaram a caracterizar as atividades agrícolas das colônias e contribuíram para a (re)adequação cultural dos colonos.

Em consonância com tal realidade, a economia primitiva do município baseava-se na agricultura, com cultivo de milho, mandioca, feijão e fumo. Na pecuária, destacava-se a criação de suínos para a engorda, de vacas para a produção de leite e seus derivados (queijo, manteiga e coalhada ${ }^{2}$ ) e de bois para o trabalho na lavoura. Usavam técnicas rudimentares em atividades simples e manuais; as terras eram férteis, aradas por tração animal (STEFFEN et al., 1984).

\footnotetext{
${ }^{1}$ Termo que designa, de forma genérica, uma etnia fruto do cruzamento entre brancos e índios.

${ }^{2}$ Leite coalhado, sem soro e temperado para usar na feitura de bolos ou para passar no pão.
} 
Atualmente, a economia do município de Chapada se baseia nas atividades agropecuárias, com destaque para a produção de soja e milho e a pecuária de gado leiteiro e de suínos. Essa característica está presente na grande maioria dos estabelecimentos rurais, geralmente de caráter familiar com pequena produção, mantendo a subsistência e garantindo a reprodução das unidades de produção familiar. A Figura 02 mostra que 856 estabelecimentos rurais com terras próprias têm menos de 20 hectares, o que representa 70,16\% dos estabelecimentos agropecuários no município. É um dado emblemático, já que segundo o INCRA, o módulo fiscal ${ }^{3}$ estabelecido para o município corresponde a 20 hectares.

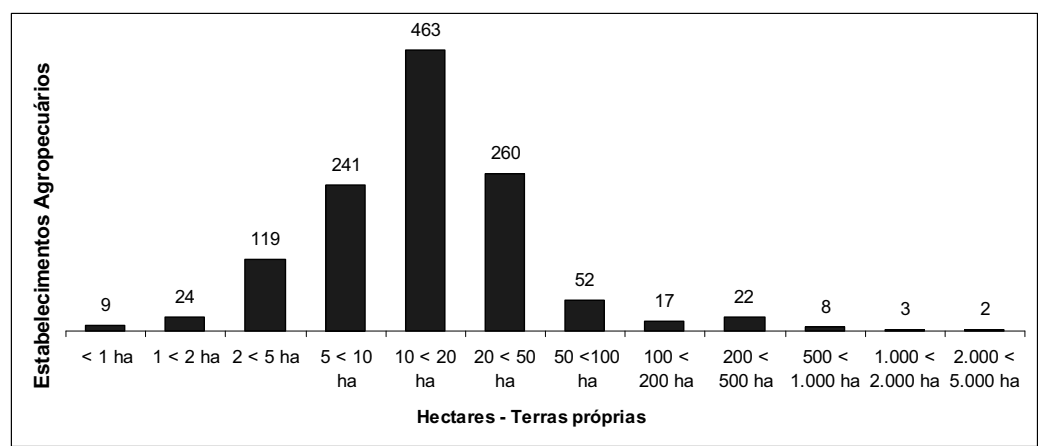

Figura 02: Gráfico dos estabelecimentos rurais com terras próprias no município de Chapada.

Fonte: Censo Agropecuário, IBGE, 2006. Org.: Sulzbacher, A. W.

Na década de 1990 iniciou-se um processo de incentivo, principalmente pelos órgãos públicos, para atividades alternativas, como a fruticultura, a piscicultura e a produção de cachaça, entre

\footnotetext{
${ }^{3}$ De acordo com o INCRA, um módulo fiscal corresponde a uma unidade de medida expressa em hectares, fixada para cada município, considerando os seguintes fatores: tipo de exploração predominante no município; renda obtida com a exploração predominante; outras explorações existentes no município que, embora não predominantes, sejam significativas em função da renda obtida e da área utilizada.
} 
outras. As políticas públicas em prol da agroindústria familiar também contribuíram significativamente para que esse processo fosse intensificado.

Contraditoriamente, em 2005, mesmo enfrentando uma série de percalços, $76,45 \%$ da área plantada no município ainda foi destinada ao plantio da soja; o trigo aparece com $12,07 \%$ e o milho com 10,06\% (IBGE, 2006).

No entanto, em Chapada vem crescendo paulatinamente a busca por novas alternativas para a agricultura familiar. Conforme dados da Emater/Ascar ${ }^{4}$ (2002), estão registradas aproximadamente 18 atividades agroindustriais, em 48 unidades de processamento, um significativo universo para o contexto rural do município.

As agroindústrias que foram selecionadas para este estudo destacam-se pelo esforço que vêm realizando no sentido de desenvolver e ampliar a atividade, pelos resultados alcançados, pela credibilidade conquistada entre a população local e regional e pelo contexto marcado pela pequena propriedade rural onde as relações de trabalho ficam restritas à mão-de-obra familiar.

Assim sendo, uma das atividades é exercida por um grupo familiar (caráter individual): a Agroindústria Familiar DEVA Delícias Naturais, que processa cana-de-açúcar e comercializa melado, schmier ${ }^{5}$, rapadura e açúcar mascavo. Já a Agroindústria Familiar Pronta Mesa beneficia e comercializa mandioca descascada empacotada in natura ou pré-cozida e embalada a vácuo. É constituída por um grupo de agricultores organizados numa associação composta por onze famílias.

Cabe destacar, ainda, que as duas agroindústrias em questão têm diferentes pontos de partida, fato que deve ser levado em conta na análise da contribuição dessa atividade para a inclusão

\footnotetext{
${ }^{4}$ Associação Riograndense de Empreendimentos de Assistência Técnica de Extensão Rural. Associação Sulina de Crédito de Assistência Rural EMATER/ASCAR.

5 Palavra alemã que designa uma espécie de doce consistente à base de melado e composto de frutas e mandioca.
} 
SULZBACHER, A.W. \& DAVID. Cesar De. Agroindústria familiar rural: ...

socioeconômica e para a valorização dos saberes locais. A AFR Pronta Mesa originou-se do desejo dos agricultores de aumentar a sua renda familiar e da disponibilidade de recursos para viabilizála, razão pela qual decidiram, em reuniões e após visitar outras agroindústrias, o produto a ser beneficiado (mandioca).

Já na AFR DEVA Delícias Naturais, a família produzia, tradicionalmente, derivados de cana-de-açúcar, principalmente melado, schmier e rapadura para a subsistência do grupo familiar. Mas o aumento da demanda pelos produtos despertou o interesse do grupo familiar em ampliar a atividade e transformar sua produção artesanal em agroindústria de processamento de cana-de-açúcar.

\section{O processamento artesanal de alimentos}

A capacidade de desenvolver técnicas para a produção de alimentos marca uma grande ruptura e diferenciação entre os grupos humanos nômades. A produção dos alimentos básicos para o consumo próprio os levaria à sedentarização. Sua evolução permitiu o desenvolvimento de técnicas que criaram estratégias para armazenar e, posteriormente, processar seus produtos, ampliando a disponibilidade e a variedade de alimentos, além de aumentar, em muitos casos, a sua qualidade.

Esse processo foi uma revolução na relação homemnatureza, pois representou, acima de tudo, a busca por superar os limites das leis da natureza que até então regiam a vida nômade. Esta primeira revolução agrícola deu início ao desenvolvimento de diferentes práticas agrícolas, cada vez mais aprimoradas, inclusive no processamento de produtos.

Remontando a um processo histórico recente, pode-se ilustrar com diferentes exemplos de como os produtos agrícolas pré-processados desempenham um papel importante e muitas vezes estratégico nas políticas econômicas, principalmente mercantis, como por exemplo: as especiarias provenientes da Índia no período mercantil; o açúcar mascavo no Brasil colônia e a economia sulina ancorada no charque, dentre outras. 
SULZBACHER, A.W. \& DAVID. Cesar De. Agroindústria familiar rural: ...

A partir da segunda metade do século XX, o processamento dos produtos agrícolas transformando-os em matérias-primas, seja para o consumo humano, seja para sua utilização no processo de produção agrícola, foi aprimorando-se e desenvolvendo diferentes estratégias de produção e comercialização.

O final da Segunda Guerra Mundial representou um salto evolutivo para a humanidade. Com a tecnologia disponível foi possível aprimorar a qualidade de vida, representada pela industrialização acelerada dos produtos. Esse processo trazia a necessidade de superar os aspectos mais arcaicos da vida, promovendo a modernização em todos os setores.

No Brasil, a modernização da agricultura iniciou-se por volta de 1960 e trouxe uma série de conseqüências, como a mudança no modo de produzir. As agroindústrias cresceram como consumidoras dos produtos agropecuários, enquanto o caráter artesanal de muitas delas cedeu lugar ao predomínio da forma industrial internacionalizada de processar, beneficiar e comercializar (MÜLLER, 1989).

No reverso das conseqüências da modernização da agricultura, começa a se revalorizar o processo de produção artesanal, resgatando-se a busca por alimentos que mantenham sua especificidade colonial e com a garantia de um produto natural e mais saudável. $\mathrm{Na}$ esteira de todo esse processo percebe-se uma carência na oferta de tais produtos, potencializando alternativas para as comunidades rurais tradicionais agregarem valor a sua produção.

\section{Do processamento artesanal para a agroindústria: interfaces de um processo emblemático}

Não há dúvida quanto à necessidade de fomentar estratégias para alavancar um novo desenvolvimento rural $^{6}$. No entanto, esse

6 Conforme Prezotto (2002b, p. 136) "Esse modelo atual de desenvolvimento rural, do qual faz parte a agroindustrialização convencional (grande escala), tem como eixo central o crescimento econômico. Isto vem implicando problemas sociais e ambientais, como 
SULZBACHER, A.W. \& DAVID. Cesar De. Agroindústria familiar rural: ...

processo exige a incorporação de novas noções sobre a agricultura e novos conceitos, como

[...] a idéia da agricultura não apenas com a aplicação de um conjunto de técnicas, mas como uma atividade humana e, portanto, devendo ser entendida com uma construção social que, além de ser ambientalmente determinada, também está subordinada a condicionantes socioculturais, caracterizan-do-se por ser um processo multilinear. Deste modo [...] é chave o conceito de coevolução porque ajuda a entender a existência de uma estreita relação entre a evolução dos diferentes sistemas culturais (dos grupos humanos) e a evolução do meio ambiente em que os grupos sociais estão inseridos (CAPORAL E COSTABEBER, 2004, p. 128).

Numa perspectiva sustentável, um desenvolvimento socioeconômico está longe de se tornar concreto no espaço rural, principalmente nas unidades de produção familiar. Contraditoriamente, esses espaços apresentam grande potencial para a construção de alternativas com relevância social, prudência ecológica e viabilidade econômica, mediante a valorização do saber social.

Trata-se de potencializar um saber social construído através de gerações, especialmente em áreas de imigração, onde o processamento artesanal dos produtos agropecuários não representa novidade: faz parte da história e da cultura do imigrante e tais produtos servem ao consumo familiar e até para abastecer o mercado local com o excedente. Diversas denominações têm sido usadas para identificar o modelo de agroindustrialização descentralizado, de caráter familiar e de pequeno porte, como "pequena agroindústria", "agroindústria familiar", "pequeno

a falta de oportunidade de trabalho, a concentração de renda e aumento da pobreza, a migração desordenada da população, em geral para os centros urbanos, o desequilíbrio ambiental, o crescimento da violência e a diminuição da qualidade de vida da população rural e, também, urbana". 
SULZBACHER, A.W. \& DAVID. Cesar De. Agroindústria familiar rural: ...

estabelecimento de industrialização de alimentos", "agroindústria de pequena escala", "agroindústria caseira" e "agroindústria artesanal", dentre outros (DIESEL et al., 2005).

Percebe-se que a busca por definir o fenômeno observado no objeto de estudo não é uma construção fácil. No intuito de encontrar uma definição muito próxima da realidade observada, optou-se por adotar o termo agroindústria familiar $\mathrm{rural}^{7}$, que passa, para fins de realização deste trabalho, a ser considerada como equipamento locado no espaço rural, que se viabiliza através do beneficiamento e/ou processamento de produtos agrícolas oriundos da propriedade familiar e explorada por seus próprios membros. As relações de trabalho contemplam o grupo doméstico ou, no caso de associações, as famílias associadas. A escala de produção da agroindústria não pode ultrapassar a capacidade de produção de matéria-prima do grupo doméstico e que, para fins de comercialização, possa atender ao mercado local e, se possível e necessário, regional. Por fim, é conveniente que o interesse pela viabilização e ampliação da atividade e por sua legalização tenha partido do grupo familiar, numa alternativa endógena identificada pelos sujeitos sociais locais e com possibilidade de melhorar sua qualidade de vida.

Sendo assim, a agroindústria familiar rural pode ser fomentada como importante estratégia para reverter as consequiências socioeconômicas da modernização conservadora na agricultura, e a participação dos agricultores familiares se torna um processo natural, uma vez que sua própria história, sua cultura passa a ser valorizada. Por isso, as políticas públicas vêm tentando retirar da informalidade a produção artesanal de alimento principalmente sob a égide da segurança alimentar. No entanto, ao mesmo tempo em que pode dar maior qualidade à produção, a legislação pode constituir-se empecilho para que a atividade se

\footnotetext{
7 Mesmo optando por essa definição, ao longo do trabalho serão respeitados os termos adotados por outros autores para designar tal fenômeno.
} 
SULZBACHER, A.W. \& DAVID. Cesar De. Agroindústria familiar rural: ...

desenvolva na pequena propriedade rural dentro das exigências legais. 
SULZBACHER, A.W. \& DAVID. Cesar De. Agroindústria familiar rural: ...

\section{Agroindústria familiar rural $D E V A$ delícias naturais}

No caso da agroindústria familiar rural (AFR) DEVA Delícias Naturais, o processo de legalização teve início em 2003 por iniciativa do grupo familiar frente ao aumento da demanda, fruto da aceitação dos produtos pela população local.

Os elementos que compõem a estrutura socioeconômica do grupo familiar estão presentes na horta, que desempenha um papel fundamental na diversificação e na qualificação dos alimentos consumidos pelo grupo familiar. Planta-se uma grande variedade de legumes, verduras e temperos, produtos também eventualmente usados na alimentação dos animais de pequeno porte (como as aves) e para a engorda de suínos, destinados ao consumo da família. A principal atividade da propriedade familiar consiste na agricultura, praticada em consórcio com a pecuária, mas em menor escala, nos 11 hectares, dos quais 4,7 são próprios. Explorações agrícolas (soja, milho, cana-de-açúcar) provêem a subsistência da família durante todo o ano.

Nesse contexto, permeado por uma crise socioeconômica, o agricultor (re)avalia seus fatores de produção - terra, trabalho e capital - e opta por desistir da atividade leiteira. No entanto, no caso analisado tal processo não culminou no êxodo rural ou em maior dependência da monocultura de soja. Representou, antes disso, na busca por novas estratégias para reproduzir a unidade de produção familiar baseadas em nichos de mercado local e na diferenciação de um produto culturalmente apreciado: o melado de cana-de-açúcar.

A opção pela produção ampliada de melado, rapadura, schmier e, eventualmente, açúcar mascavo ocorreu justamente a partir da percepção da existência de mercado consumidor em expansão, disposto a pagar por um produto acima de tudo cultural, de qualidade e diferenciado daqueles encontrados nas redes convencionais de comercialização. Constatar a existência desse mercado é fundamental antes de optar pela atividade, e foi possível através de um estudo das potencialidades de absorção da produção. 
SULZBACHER, A.W. \& DAVID. Cesar De. Agroindústria familiar rural: ...

Para viabilizar o processo de legalização, o grupo familiar teve de superar vários obstáculos, devido ao pioneirismo desse tipo de atividade no município, pela falta de recursos próprios e pela escassez de informações quanto ao processo de constituição da agroindústria (legislação sanitária, ambiental, registro etc). Atualmente, ao avaliar toda essa trajetória, o grupo familiar enfatiza e reconhece a fundamental importância do apoio e da orientação que receberam do extensionista da Emater/Ascar. No depoimento $^{8}$ a seguir percebe-se como a agroindústria foi importante para qualificar e ampliar a produção:

[...] as horas de serviço são as mesmas, só que é mais fácil (pausa) a gente não pára de trabalhar, o serviço continua, porque agora a gente tem mais, porque na outra vez a gente fazia só em um tacho, agora tem dois e nós fizemos quatro por dia. Antigamente nós só fazia um tacho de melado por dia e ainda entrava noite adentro; agora não, com essa instalação nós fizemos quatro tachada (...) as horas de serviço aumentaram, só que é mais fácil se antes dava $30 \mathrm{~kg}$ por dia, hoje dá $120 \mathrm{~kg}$. Se era para continuar como antes, nós não ia agüentar.

Com o incremento de tecnologias simples, adequadas à realidade da exploração familiar, foi possível ampliar a escala de produção e qualificar o produto, uma vez que o batedor ${ }^{9}$ garante que o produto seja misturado de forma homogênea e constante, impossível no trabalho manual. Esse elemento 'novo' no processamento do produto artesanal garantiu inclusive a melhoria da qualidade do produto, principalmente de sua aparência, fato que também interfere na escolha do produto pelo consumidor, como já

\footnotetext{
${ }^{8}$ As entrevistas foram semi-estruturadas, permitindo ao grupo familiar relatar o processo de consolidação da atividade. Priorizou-se a participação de todos os membros da família.

${ }^{9}$ Instrumento similar a uma batedeira doméstica construída por iniciativa do grupo familiar com tecnologia inspirada em equipamentos de outras agroindústrias de melado e açúcar mascavo e.
} 
SULZBACHER, A.W. \& DAVID. Cesar De. Agroindústria familiar rural: ...

foi verificado por Neumann et al., 2006; Prezotto, 2002; Guimarães, 2001, dentre outros.

Percebe-se que a adoção de tecnologia adequada à realidade do pequeno estabelecimento rural apresenta grande potencialidade para qualificar a produção e, principalmente, diminuir o uso da força manual, concordando com o raciocínio de Graziano da Silva $(1999$, p. 17) "o homem necessita aumentar a sua capacidade de produzir, porque isso the possibilitará, inclusive, trabalhar menos [...] sempre o homem procurou inventar coisas que lhe facilitassem a labuta diária".

Por fim, destaca-se que a agroindústria familiar rural DEVA Delícias Naturais nasceu de um processo endógeno, marcado pela busca de estratégias para garantir a reprodução da unidade de produção familiar. Foi viabilizada pela união de forças, representadas principalmente pela persistência do grupo familiar e pela contribuição de órgãos públicos, como a Emater e a Prefeitura Municipal. O processo de constituição foi permeado pelas mais diferentes dificuldades, que foram sendo paulatinamente superadas pelo (re)apreender a produzir, fundamentalmente marcado pela relação dialógica.

O desenvolvimento da DEVA garantiu ao grupo familiar um acréscimo significativo de renda, o emprego da força de trabalho familiar e eventualmente dos vizinhos ou parentes; e, principalmente, permitiu à propriedade rural uma autonomia em relação às empresas agroindustriais. A inclusão social foi decorrente de todo esse processo, uma vez que a venda direta do produto ao consumidor permitiu ao agricultor ampliar suas relações sociais, passando a ser conhecido no município como 'tio do melado'.

Dentre os fatos que demonstram a aceitação do produto e a credibilidade do grupo familiar entre os munícipes, órgãos públicos e imprensa local, destaca-se o prêmio Destaque Rádio Simpatia, recebido em novembro de 2006, por seu desempenho no ramo agroindustrial e recebido com surpresa, porque não se esperava tamanho reconhecimento da população chapadense. 
SULZBACHER, A.W. \& DAVID. Cesar De. Agroindústria familiar rural: ...

\section{Agroindústria familiar rural pronta mesa}

Vários fatores contribuíram para a emergência da AFR Pronta Mesa, entre os quais se destacam: os bons resultados alcançados pela DEVA, os recursos públicos disponíveis e, principalmente o incentivo da Emater. No entanto, o fator principal foi a motivação do grupo em relação à atividade, elemento indispensável na superação de todos os desafios enfrentados para transformar o sonho em realidade.

O primeiro passo, então já realizado, era a concepção da associação 'Grupo de Agricultores Junto Venceremos' (GAJV) criada em junho de 1999 com o objetivo de promover a organização global dos estabelecimentos rurais e a busca de alternativas de renda para as famílias, dentre outros. Em 2000 foi iniciado o longo périplo pelos caminhos da burocracia para obter seu registro como pessoa jurídica. Na seqüência da busca de alternativas para as famílias que compunham o grupo, surgiu a possibilidade da agroindústria, que se concretizaria com a opção pelo beneficiamento de mandioca.

Estudos realizados apontam alguns elementos característicos da realidade socioeconômica dos estabelecimentos agrícolas que compõem o GAJV: em média, os homens têm 45,6 anos de idade enquanto as mulheres têm 41,2 anos, formando uma população em idade ativa; a média de filhos por família é em torno de 2,09 , o que bem demonstra a disponibilidade de força de trabalho nos grupos familiares; a maioria dos adultos estudou somente até a quinta série do ensino fundamental, dentre outros fatores, devido ao importante papel que os filhos desempenhavam (por volta de 1960) como força de trabalho, para garantir a reprodução das unidades de produção familiar; a média de área própria é de 11,28ha, ou seja, muito abaixo do módulo fiscal do município, estipulado em $20 \mathrm{ha}$.

$\mathrm{Da}$ análise desses dados conclui-se que as propriedades, além de constituírem-se em pequenos estabelecimentos, mantêm como característica a diversificação da produção, para consumo do grupo familiar e, eventualmente, para comercialização. Outra questão importante refere-se aos implementos agrícolas: por seu 
SULZBACHER, A.W. \& DAVID. Cesar De. Agroindústria familiar rural: ...

pequeno porte, nenhum dos estabelecimentos dispõe de todos os equipamentos para o preparo da lavoura, plantio e colheita, por isso ocorre o empréstimo (ou troca de serviço) de equipamentos entre vizinhos, parentes ou com outra associação. A força de trabalho resume-se ao grupo familiar ou a parentes próximos; muitos agricultores enfatizaram a necessidade de contratar mão-de-obra eventual, mas não o fazem por falta de condições para remunerá-la.

Construir um grupo conciso de agricultores não é fácil, principalmente pelo contexto histórico de reprodução das unidades de produção familiar, marcadas pelas decisões individuais do grupo familiar e movidas por seus interesses. No entanto, favorável a esta construção, estão os laços de sociabilidade presentes nas comunidades rurais e geralmente fortalecidos nos encontros na "bodega" 10 , na igreja e no jogo de futebol, dentre outros espaços.

Os agricultores vêm buscando, progressivamente, o trabalho coletivo como estratégia para viabilizar seus empreendimentos, principalmente para melhorar a propriedade e, consequentemente, a qualidade de vida do grupo familiar. Este elemento em destaque foi muito importante para promover a construção, viabilização e organização produtiva da AFR Pronta Mesa.

Silveira e Heinz (2005) também compreendem a cooperação como elemento agregador no processo de viabilização da produção artesanal onde a solidariedade e compartilhamento de objetivos e metas é a alavanca da economia solidária em gestação. Pedagogicamente, o aprender coletivo é essencial para possibilitar a troca de experiências e conhecimentos e na definição de processos cooperativos e na descentralização necessária dos interesses individuais que possam vir a gerar conflitos no grupo e dividir esforços.

Além de um coletivo bem organizado, é fundamental que a construção da agroindústria esteja nas mãos dos agricultores, sob

${ }^{10}$ Termo regional, designa pequeno estabelecimento comercial localizado nas vilas das comunidades onde geralmente as pessoas (principalmente os homens) se reúnem nos finais de semana para atividades de lazer, como jogar carta, bocha e outros. 
SULZBACHER, A.W. \& DAVID. Cesar De. Agroindústria familiar rural: ...

sua responsabilidade. Na construção da Pronta Mesa, o GAJV teve de reorganizar-se. Nesse processo, houve o incremento da área plantada de mandioca em praticamente todas as propriedades familiares. No entanto, foi fundamental a organização para o beneficiamento da produção na agroindústria. Como as atividades eram novas, o grupo passou por cursos de qualificação e, no decorrer do processo, foram acordadas regras paulatinamente discutidas e, se necessário alteradas, para que tudo caminhasse no sentido de promover o bem-estar dos associados, conforme o depoimento:

[...] no início foi dificil até todo mundo aprender a fazer o beneficiamento. Na primeira vez, ninguém queria descascar, ninguém queria lavar, porque a água era muito fria no inverno e daí nós fizemos o seguinte: aqueles que trouxeram a mandioca tinham que lavar. Dai a regra era assim até que enfim deu certo, quando terminava de descascar todo mundo ia embora daí ficava sempre os mesmos para limpar a agroindústria. Daí a gente decidiu que quem trazia a mandioca tinha que limpar e virou regra. Tudo isso foi decidido em grupo! (AF08).

Além disso, cabe destacar outro elemento importante que é a identidade do/para com o grupo. Um dos principais problemas apontados pelos associados foi a falta de diálogo que, por vezes, pode comprometer o desenvolvimento e inviabilizar a atividade. Percebe-se claramente como a cooperação é importante: o sentimento de pertencimento e/ou identidade com a atividade do grupo que ali se encontra, semanalmente, já é um passo para transformar os problemas e/ou dificuldades em diálogo, superação e aprendizado, etapa essencial para consolidar a união do grupo, prevalecendo os objetivos coletivos gerados em torno da agroindústria.

Essa identidade inicial existe pelo próprio fato de todos conviverem na mesma comunidade. No entanto, quando a questão é o desenvolvimento de uma atividade que vai exigir a participação de todos em suas diferentes dimensões, tal identidade precisa ser 
SULZBACHER, A.W. \& DAVID. Cesar De. Agroindústria familiar rural: ...

aprimorada através da própria qualificação das relações sociais, de tal forma que todos conheçam as causas dos problemas, saibam eliminá-las e respeitem as opiniões contrárias, processo que, acima de tudo, precisa ser realizado no interior do grupo.

Embora a participação da mulher ainda seja conflituosa, deve ser estimulada, principalmente porque, no espaço rural, a mulher tem sido tradicionalmente relegada a segundo plano no âmbito das decisões em torno da propriedade. Historicamente, o homem assume uma função de chefe do lar e, portanto, toma as decisões, consultando a família só eventualmente. No caso da agroindústria individual, a mulher assumiu papel estratégico na tomada de decisões sobre o processo de produção, ficando a administração, a venda e a comercialização a cargo do companheiro.

Já na agroindústria coletiva, a mulher contribui de forma substancial durante o processo de produção, principalmente no descasque da mandioca. No entanto, quando questionadas acerca da participação nas reuniões e/ou assembléias, muitas delas revelam que não se sentem 'convidadas' e os homens decidem tudo; e, por não serem ouvidas, não têm interesse em participar. Essa é uma questão particularmente importante a ser discutida, principalmente no contexto tradicional do espaço rural. Como Freire (1977, p. 49) ressalta, seja como for, com maior ou menor dificuldade, não será com o antidiálogo que romperemos o silêncio camponês, mas sim com o diálogo em que se problematizem seu próprio silêncio e suas causas.

Por fim, muitos foram os pontos positivos apontados pelos entrevistados, entre os quais se destacam os momentos de descontração e sociabilidade favorecidos pela atividade que reúne os associados em torno da mandioca, contando histórias, piadas e fazendo brincadeiras. Outra questão fundamental foi a geração de renda, que não vem sendo muito expressiva, mas há grande expectativa de que venha a ocorrer, garantindo a reprodução das unidades de produção familiar. 
SULZBACHER, A.W. \& DAVID. Cesar De. Agroindústria familiar rural: ...

Percebe-se que a atividade vem se constituindo como alternativa para a agricultura familiar, em vários aspectos: estímulo à participação e à organização coletiva, em busca do desenvolvimento local; emprego da força de trabalho familiar; geração de renda promovendo a (re)inserção das pessoas no processo produtivo; promoção de espaços de sociabilidade, e a organização necessária para viabilizar a agroindústria que estimula os agricultores a buscarem fontes alternativas e terem participação política mais ativa na vida social. Esses aspectos contribuem fundamentalmente para a construção da cidadania no espaço rural.

A territorialização da agroindústria familiar promove uma série de transformações neste espaço que se expressam na própria (re)organização da propriedade, tendo em vista a diversificação, até a construção da cidadania que se expressa na participação política, discutindo e resistindo a processos que não atendem aos seus interesses.

\section{As estratégias continuam, basta valorizá-las!}

Por fim, as potencialidades da produção familiar para uma transformação do espaço com desenvolvimento rural sustentável são variadas. Orientá-las a fim de garantir a melhoria da qualidade de vida dos agricultores se configura responsabilidade social. Para tanto, é imprescindível estudar a realidade e valorizar os sujeitos sociais que a transformam cotidianamente.

A valorização das estratégias que se apresentam viáveis, dentre as quais agroindústria familiar rural, precisa ocorrer paulatinamente de forma a criar um ambiente de discussão que promova a construção de novas possibilidades, motivadas principalmente pelos jovens. Esse público especificamente, que vem deixando o campo em busca de emprego nos centros urbanos, precisa aprender a criar estratégias de desenvolvimento local, estratégias essas que demandam planejamento e incentivo público.

Finalmente, conclui-se que a atividade atinge seus objetivos enquanto promotora da inclusão socioeconômica dos agricultores, demarcada inicialmente através da troca de experiências e 
SULZBACHER, A.W. \& DAVID. Cesar De. Agroindústria familiar rural: ...

formação do grupo, seguida pelo estreitamento dos laços de sociabilidade e a geração de renda para as famílias. Além disso, a parceria firmada entre a AFR Pronta Mesa e a AFR DEVA Delícias Naturais foi muito importante, principalmente para a própria redução de custos na construção e pelas experiências já acumuladas desta última.

\section{Referências bibliográficas}

CAPORAL, F. R. e COSTABEBER, J. A. Agroecologia e Extensão Rural: contribuições para a promoção do desenvolvimento rural sustentável. Brasília: MDA/SAF/DATERIICA, 2004.

DIESEL, V. et al. Caracterização da agroindústria familiar de aguardente de cana-de-açúcar na região da Quarta Colônia. In: I Congresso Internacional de Desenvolvimento Rural e Agroindústria Familiar, 2005, São Luis Gonzaga-RS. Anais do I Congresso Internacional de Desenvolvimento Rural e Agroindústria Familiar. São Luis Gonzaga: URI, 2005. v. único. p. 315-323.

EMATER/ASCAR. Diagnóstico da Realidade Municipal de Chapada. 2002.

FERREIRA, D. A. de O. Mundo rural e geografia. Geografia Agrária no Brasil: 1930-1990. São Paulo: Editora UNESP, 2002.

GRAZIANO DA SILVA, J. Tecnologia e agricultura familiar. Porto Alegre: Ed. Universidade/UFRGS, 1999.

GUIMARÃES, G. M. A legislação industrial e sanitária dos produtores de origem animal: o caso das agroindústrias de pequeno porte. 2001. 146 f. Dissertação (Mestrado em Extensão Rural) - Universidade Federal de Santa Maria, Santa Maria, 2001.

INSTITUTO BRASILEIRO DE GEOGRAFIA E ESTATÍSTICA (IBGE). Cidades. Disponível na Internet: $<$ http://www.ibge.gov.br/cidadesat/d.php>01 ago. 2006. 
SULZBACHER, A.W. \& DAVID. Cesar De. Agroindústria familiar rural: ...

JORNAL DE CHAPADA. Produção de melado: outra opção de renda. 23 jun. 2006. p. 7.

17 mar. 2006. p.12.

Vila Rica inaugura hoje agroindústria de mandioca.

MINISTÉRIO DA INTEGRAÇÃO NACIONAL. Projeto Agroindústrias Familiares - 2003. Diagnóstico Unidades Agroindustriais - Mesorregião Grande Fronteira do Mercosul. Relatório Final, Francisco Beltrão/PR, 2004.

MIOR, L. C. Agricultores familiares, agroindústrias e redes de desenvolvimento rural. Chapecó: Argos, 2005.

MÜLLER, G. Complexo Agroindustrial e modernização agrária. São Paulo: Hucitec: EDUC, 1989.

NEUMANN, P. S. et al. Diagnóstico e cadastro das unidades de produção de hortigranjeiros e de produtos coloniais da microrregião da Quarta Colônia e Estudo Regional de mercado na região central do Estado. Relatório de Pesquisa FAPERGS. Grupo de Pesquisa Sociedade, Ambiente e Desenvolvimento Rural e Núcleo de Estudos em Economia Agroalimentar da UFSM-RS. 2006.

PREZOTTO, L. L. Qualidade Ampla: referência para a pequena agroindústria rural inserida numa proposta de desenvolvimento regional descentralizado. In: LIMA, Dalmo M. de Albuquerque e WILKINSON, John (Org.) Inovações nas tradições da agricultura familiar. Brasília: CNPq/Paralelo 15, 2002a. p 285-300.

Uma concepção de agroindústria rural de pequeno porte. In: Revista de Ciências Humanas. EDUFSC. Universidade Federal de Santa Catarina. Centro de Filosofia e Ciências Humanas. Florianópolis. n. 31, abr. 2002b. p.133-154. RAMBO, B. S. J. A fisionomia do Rio Grande do Sul. Jesuítas no Sul do Brasil. Porto Alegre: Livraria Selbach, 1956. v. 6.

RAMBO, B. S. J. A fisionomia do Rio Grande do Sul. Jesuítas no Sul do Brasil. Porto Alegre: Livraria Selbach, 1956. v. 6. 
SULZBACHER, A.W. \& DAVID. Cesar De. Agroindústria familiar rural: ...

ROCHE, J. A colonização Alemã e o Rio Grande do Sul. Porto Alegre: Globo, 1969.

SILVEIRA, P. R. C. da; HEINZ, C. Controle de qualidade normativo e qualidade ampla: princípios para re-estruturação e qualificação da produção artesanal de alimentos. In: I Congresso Internacional de Desenvolvimento Rural e Agroindústria Familiar, 2005, São Luis Gonzaga-RS. Anais do I Congresso Internacional de Desenvolvimento Rural e Agroindústria Familiar. São Luis Gonzaga: URI, 2005. v. único. p. 1-9.

STEFFEN, R. J.; STEFFEN, I. M. L.; STEFFEN, N. S. Histórico do Município de Chapada. Chapada: Editora da UPF, 1984.

WILKINSON, J. O estado, a agroindústria e a pequena produção. São Paulo: HUCITEC-CEPA/BA, 1986.

Recebido em novembro de 2007

Aceito em outubro de 2008 